\title{
Adaptation Meta-Cognitive as an Educational Tool: Animated Puzzle
}

\author{
Ida Syakirah Sudin, Suzana Ahmad, Marina Ismail, Norizan Mat Diah \\ Faculty Science Computer and Mathematic, Universiti Teknologi MARA Shah Alam 40450 Selangor, Malaysia
}

\begin{tabular}{|c|c|}
\hline Article Info & ABSTRACT \\
\hline Article history: & $\begin{array}{l}\text { Students need to be equipped with high order thinking skill in order to } \\
\text { prepare them with future world. Eventhough variety of programs on teaching }\end{array}$ \\
\hline Received May 23, 2018 & high order thinking skills has been implemented formally in schools in \\
\hline Revised Jun 24, 2018 & Malaysia and also placed in the school curriculum, the results are not to the \\
\hline Accepted Jul 8, 2018 & $\begin{array}{l}\text { satisfactory. This research is proposing a suitable educational tool which can } \\
\text { increase higher thinking skills among students. Keeping in mind that learning }\end{array}$ \\
\hline Keywords: & $\begin{array}{l}\text { components: cognitive learning achievement, meta-cognition and motivation, } \\
\text { an educational game with Meta-cognitive activity is proposed. An animated }\end{array}$ \\
\hline Animated puzzle & puzzle game that adapts acitivities that enables to nurture meta-cognitive \\
\hline Educational game & skills has been developed and tested. Heuristic testing and functionality \\
\hline Educational tool & testing has been done towards the project prototype and positive results has \\
\hline Meta-cognitive & $\begin{array}{l}\text { been obtained. An enhancement of prototype will embark a new perspective } \\
\text { of educational mechanism and could improve students higher order thinking } \\
\text { skills capability. }\end{array}$ \\
\hline
\end{tabular}

Copyright $\odot 2018$ Institute of Advanced Engineering and Science. All rights reserved.

\section{Corresponding Author:}

Ida Syakirah Sudin,

Faculty Science Computer and Mathematic,

Universiti Teknologi MARA,

Shah Alam 40450 Selangor, Malaysia.

Email: idasyakirahsudin95@gmail.com

\section{INTRODUCTION}

In today's era, of fast data thinking skills is viewed as a very important component skill [1]. The utilization of the mind to make splendid thoughts, make decisions and comprehend problems are the characteristics of thinking skills [2]. Meanwhile, more than 10 years the program teaching high order thinking skill (HOTS) has been implemented formally in schools in Malaysia and the program begins to get place in the school curriculum [3].

However, Malaysian Education Ministry confront numerous issues in the usage of HOTS in learning and teaching since it is just brought restricted accomplishment until now [2]. The National Average Grade (GPN) in 2013 has reported that the overall performance of UPSR candidates in 2014 has decreased by 0.02 . In the meantime, through the Blueprint for making Malaysia an international level in education, various efforts and transformation have been undertaken in the field of education in order to improve higher order thinking skills [2].

In addition, Malaysia's result in the Programmed for International Students Assessment (PISA) and the Trends in International Mathematics and Science Study (TIMSS) has also been decreased from 2007 to 2012. The format of the question is one of the factors that contributed to the results. The format for the PISA questions are in the form of long content and the students have to make an interpretation while format for the Malaysian public examination questions, the students just have to focused in Figures and Tables [2].

One of the approach of improvement is adaptation of meta-cognitive activity through teaching and learning in schools [2]. Base on the research [4], a student who has difficulty to solve problems based on cognitive and meta-cognitive is due to lower level of thinking skills. This research is to explore an 
educational tool as an alternative method that can nurture high order thinking skills among Malaysian students and in the long run to improve the ranking of Malaysian students' assessment. This research will also accomodate e-learning system that have been set up in the ICT infrastructures. E-learning may support conventional teaching approach in Malaysian educational program. This is to variate the learning environment to enhanced and improve the problem faced by students with poor critical thinking ability.

A prototype of a maze with animated puzzle game that adapts activities that enables to nurture metacognitive skills an educational tool has been developed. It is constructed for children aged between 7 to 8 years old who are facing problem in high order thinking skills. This educational tool is designed to suit Malaysian environment and apart from that, it is using Malay language. In addition, this educational tool is adapting gaming approach and it can be delivered on desktop for the users to run the application. This paper will discuss further on research background, methodology, design and testing of this prototype.

\section{RESEARCH BACKGROUND}

According to Kiili [5], learning is defined as a development of cognitive structures through activity or practice in the game world. While Mayer [6] expressed, learning is conceptualized as a multidimensional development involving three components, which are: cognitive learning achievement, meta-cognition and motivation. Both of this definitions are fundamental to Ruggiero [7] statements who stated that, meta-cognitive learning can adapt children in learning as they build their own comprehension of the world and build their comprehension thus develop higher order thinking skills through this active process.

Normally, children required thinking independently when they get an establishment of specific learning. These skills includes the ability and disposition to recognize cause-effect relationships [8], use casual rationale in making analogies and speculations [8], become aware of and control their own emotions [9], become empathic of others [9], and think abstractly [10]. These skills and ability need to be activated in order for a children to apprehend a subject with accomplishing higher levels thinking of meta-cognitive while learning.

Meta-cognitive is significance to be nurtured in every children to increase conscious ability to comprehend, control, and manipulate children's own cognitive process and awareness of children's own knowledge. In another words, meta-cognitive skills enable students to master information and solve problem more easily. Besides, students also are able to plan, setting goals, initiating work, sustaining future-oriented problem solving activities, observing and overseeing progress on tasks to detect and correct errors, thus keeping track of the effect of one's behaviour on others. Meta-cognitive skill has three parts such as meta-memory, meta-comprehension, and self-regulation [10]. All of these three parts can be engaged simultaneously while playing game.

\subsection{Learning While Gaming}

Gaming can support the improvement of learning communities by offering experiential learning in encouraging the development of meta-cognitive thinking skills. Games have been recognize by the educational theorists and researchers as a potentially powerful resources [12] to help learning process. According to McFarlane [13], games can be powerful tools for supporting learning, and a lot of research are being done on games in education. This has been supported by Wheelihan [14] who said that games could continually provide challenges and goals to the players as an interactive activities, and to master the game mechanics they will need to involve into an active learning process which normally engaged subconciously.

These days, playing computer games gives learner a "mental workout"; that the structure of activities enhances various cognitive skills which are embedded in a computer games and it have been contended by the researchers. There are lots of games that the players are gone up against with a surge of both long and short lived decisions, and must arrange critical thinking techniques which incorporate watching a course of action complex errands such as crossword puzzle, Sudoku puzzle, or jigsaw puzzle [15].

\subsection{Maze Blocks Puzzle Game}

Maze puzzles game is a board game where a player must achieve the finish process of a maze as the emitted maze is being defined on the game board. Maze puzzles included an endorsed maze blocks arrangement where a player must progress from the begin through the maze until the recommended finish [16]. Therefore, the design of this is to provide a game with a game board outlining a majority of regions and the board is formed in order to secure a majority of partitions between the regions. However, every type of puzzles has their own level of difficulty to be solved. The simplest puzzles for children only have a few pieces while adult puzzles may have thousands [17]. The fewer pieces a puzzle has, the larger they tend to be. This is perfect for young children who are not ready to manipulate small objects or who still have a tendency to put things in their mouths. Older kids can handle puzzles with more pieces and may be 
comfortable assembling 50 pieces or 100 pieces puzzles on their own [18]. Adults who do not mind spending some time on assembly can get enjoyment from sorting hundreds, or thousands, of small pieces and fitting them together. It is within the mental and physical limit of most adults to develop a jigsaw of astounding complexity but the same cannot be said for children and do not want to put them off by giving them something too difficult. Suggestions for different age groups are as follows:

Table 1. Number of Puzzle According to Ages [18]

\begin{tabular}{lc}
\hline Age 1 to 2 years old & Less than 10 pieces \\
\hline Age 3 to 4 years old & 10 to 20 pieces \\
Age 5 to 6 years old & 20 to 30 pieces \\
Age 7 to 8 years old & 30 to 40 pieces \\
\hline
\end{tabular}

Advantages of playing maze blocks puzzle are the players may control blocks to move blocks into their right places. We view it as immediate position activities. Then, the players may control blocks on course to their right position in light of the fact that doing as much makes mental operations of visual search, picture representation and spatial rotation less demanding to perform by offloading part of every operation to physical activity in the environment [16]. These are view as indirect position activities. In addition, the players will regularly investigate the problem space for examples; sort out puzzle blocks into gathering containing corner blocks, edge blocks, or blocks of the similar color or shape. These activities are produce through changing the environment in a simplification of the task [19] which called as exploratory activities.

\section{OTHER SIMILAR RESEARCH}

Many examples of previous researchers have developed various types of puzzle game and using different kind of techniques to develop it. All the techniques have extremely unmistakable outline and research groups bringing about many cases from exceptionally particular methods of insight about education. Although these distinctions, there are favorable circumstances to considering the interactive multimedia elements as each has its own technique and thoughts that will improve the weak skills of the learners.

A game application by Carvalho [20] has been produced for Android platforms which permit users to solve musical puzzles. The market accessible solutions are still established on the original concept, comprehending visual jigsaw puzzles. Carvalho [20] envisioned a musical puzzle game without any visual feedback where the main objective is to reconstruct a fragmented song by putting each individual segment in the correct order. The concept is based on the conventional cardboard puzzles games as well as an application previously developed [20].

Another interesting research is Audio Puzzler [21]. Audio Puzzler [21] has been developed for online puzzle game that uses speech audio as the basis for the puzzle pieces. At the outset, each puzzle grouped by color to simplify the puzzle and starts as a set of audio bubbles. Audio bubble will pops the bubble if the users double-clicking it and the audio in that particular bubble will play. Then, interfaces that are displayed are allowing the players to enter the words that were spoken in the audio. By clicking an icon or pressing a key combination the audio can be repeated and once it have done, the textual puzzle pieces can be dragged on top of one another to connect them. If the text is same and their position is next to each other, the particular words are color in green but if the words do not match, then they are color in red.

SJPA or smart jigsaw puzzle is another research done educational game [22]. The researcher have planned and prototypically executed a smart jigsaw puzzle game based on latest Radio Frequency Identification (RFID) innovation. With that, small miniatures are tagged on every single pieces of a puzzle game and the Smart Jigsaw Puzzle Assistant (SJPA) application is developed [22]. The SJPA application is tested on a computer and the current status of the physical jigsaw puzzle is closely monitors. Whenever the player chooses a new piece of the physical jigsaw game to be added to the previously combined pieces on the table, the users will scans it with a handy RFID reader that is connected to the computer. The pieces that have been added will automatically recognized by the SJPA. Then it will update the status of the jigsaw game on the computer screen [22].

The successful of all these three projects had resulted in nurturing meta-cognitive ability in children. As for the prototype for this research a semiotic level which it will concern the users about what is changing in the animation has been adapted. This prototype has inhibiting function system that used as this system which spares learners from rationally re-enacting the working of the application compare to the other three research that had been discussed earlier. Apart from that, this project are designed according to the design principles of animation which are apprehension principle and flexibility principle. For apprehension principle, it is suitable to be adapted because this project will designing for $2 \mathrm{D}$ illustration and this principle stated the realism is not suitable when the main objective is to enable the learners to understand the content 
of the game. While, for flexibility principle this project will using this principle because the information will be clearly provided in the animation. Besides, it will give some knowledge and interest to the learners about the animation technique that will be applied since this technique has not been used in previous research when developing puzzle game.

\section{METHODOLOGY}

The development of this prototype is based on the waterfall model. The headway of waterfall model is viewed as gushing tenaciously, downwards as a waterfall, in which it is a progressive outline prepare model as often used in developing software. The waterfall development cycle has several stages such as requirement analysis, system design, system implementation and system testing. This is the starting stage of the framework advancement life cycle (SDLC) in which all conceivable framework necessities are found and evaluated. Programming prerequisites detail incorporates the total information about how genuine end users are suspecting from the framework. This accomplish covers all the essential prerequisites for the improvement of errand. Finally, after culmination of prerequisites collecting and investigation, a necessity detail report is made which it gives out as a data to the next stage of SDLC.

In this stage the framework and programming configuration is set up from the necessity determination that is contemplated in the principal stage. Framework configuration helps in indicating equipment and framework necessities furthermore helps in characterizing general framework engineering. The framework plan particulars serve as contribution for the next stage of the model. In the wake of getting the framework outline determination detail the genuine coding may be started. At the point when starting the genuine coding, necessities are apportioned into the model or units. The genuine coding are first create to the framework called units. In the wake of realizing all units, the coordination may be started in the next stage. The build unit's model design is tried freely in this phase to check if the unit models are meets the predefined prerequisites and this model testing is called as Unit Testing.

In the past model the framework prerequisites are detached into models and each model is created and tried autonomously. In this phase all units are consolidated and done the framework testing to check if every one of the models or units are joined legitimately or not and the framework as whole doing as detail as per the framework prerequisites report, so this stage as the System Testing. This application has been tested and the heuristic evaluation form has been distributed to the three chosen experts that specialized in metacognitive study. The heuristic evaluation form is categorised in two category which are interface and interactivity; and content. The motivation behind this heuristic evaluation form is to obtain their opinion about this educational tool and also their desire and recommendation in order to enhance the application.

\section{PROTOTYPE DESIGN}

Home screen is designed based on the figure and ground principle. This outlines makes an adjustment in the ground that characterizes the state of the figure, including shading that makes a temperament, or setting up a reference point like place. Figure 1 is an screen shot of what the user will first notice and process.

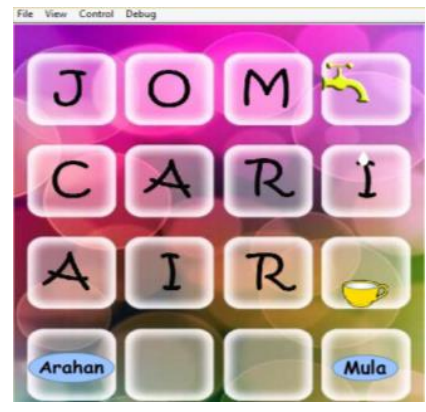

Figure 1. Home screen design

This prototype project uses a background of circles shape as the ground and for the figure this project uses a shape of squares which is located parallel on the screen. After that, inside the squares there is a title of the application which is named 'JOM CARI AIR'. Also at the bottom of the screen there is a play 
button which named 'Mula' that user can click the button to start play the game and an instruction button which named 'Arahan' that user can click the button before start playing the game.

For game screen it is designed as shown below in Figure 2. The buttons, font style, font size, and colours are designed based on consistency and standards principle. The buttons in this application is designed in reliable on the screen, has utilize the standards wording in labels and messages and utilize a consistent colour scheme throughout. Furthermore, the interface of the application is consistent that empowers the users to build an exact mental model of the way it works.

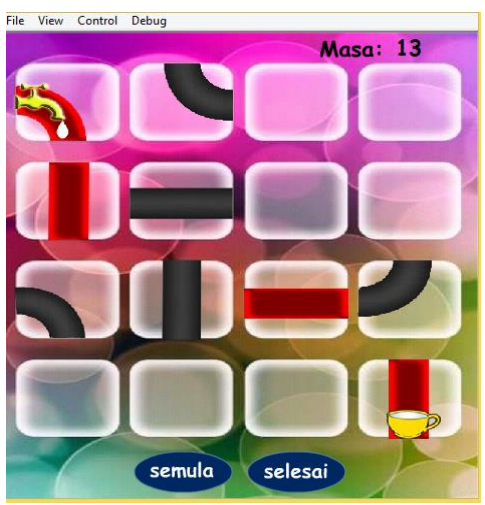

Figure 2. Game Screen Design

The colour of blocks puzzle in this project is using red colour and black colour. Red colour is for starting and finishing blocks while black colour is for users to solve the task. The total blocks for this project is 9 pieces. The font style of the timer is using times new roman, size of 12 and using black colour. The reset and done buttons are in the form of icon and also text to represent the meaning of icons.

To create motion-tween animations, this project create a tweened instance on a traverse of frames, then make one or more changes somewhere on that traverse of frames. Flash then creates the animation that would occur to transition between those changes. Flash varies the object's size, rotation, colour, filter or different characteristics between the changed frames that have made to create the appearance of movement or motion, such as an instance moving across the stage or fading in and out or both in the meantime.

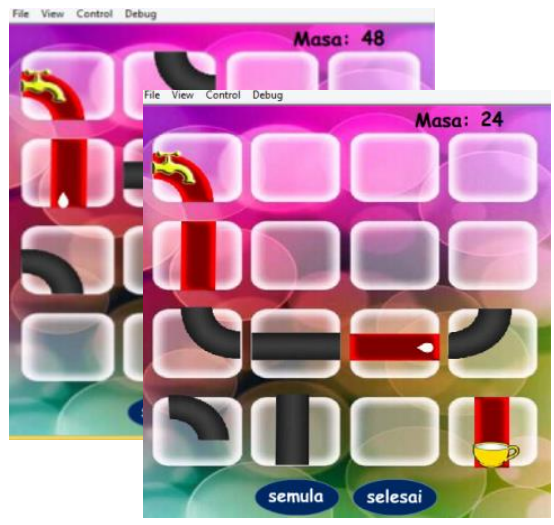

Figure 3. Animated screen design

For this project, this motion tween is applied to create an animation of moving object after the users have done their task. Figure 3 shows the screenshots of object starts to animate and finish animating.

\section{TESTING}

This section discussed on the system testing regarding the data collected during the functional testing session and heuristic evaluation testing session; and the summary of this project including the objectives that have been achieved, contribution of the project, project limitation and recommendation for 
future enhancement. The result finding is gained by analysing data that collected from functional testing and heuristic evaluation testing. This application is tested and the heuristic evaluation form is distributed to get the feedback from the experts.

This application has been tested and the heuristic evaluation form has been distributed to the three chosen experts that specialized in meta-cognitive study. The heuristic evaluation form is categorised in two category which are interface and interactivity; and content. There are ten questions that are listed in interface and interactivity category while five questions that are listed in content category. After read the questions, the experts will evaluate the questions based on the options given. There are four options that are provided in the evaluation form such as cosmetic level, minor level, major level and catastrophic level. Also, the experts can write any possible solutions or recommendations for the application in the text box provided. Furthermore, according to Nielsen [23], the optimal number of evaluators is from three to five evaluators. The motivation behind this heuristic evaluation form is to obtain their opinion about this educational tool and also their desire and recommendation in order to enhance the application. Two perspectives are been explored for this testing method which are interface design and deliverable perspective.

Three experts have been chosed to evaluate the project prototype. First expert is someone who specialized in signal processing, speech processing and computational linguistics, Second expert is someone who is specialized in game based learning, gamification and multimedia pedagogical agent and the Third expert is someone who is specialized in computer games, multimedia education, educational computer game and real time feedback algorithm.

\section{First Expert}

The first expert is satisfied and happy with the interface and interactivity of the project prototype. As for content and deliverable perspective, expert is also satisfied, enjoyed and engaged with the project prototype while she were testing it.

Second Expert

Second expert is satisfied and impressed with the interface and interactivity or the project prototype. For content and deliverable perspective, expert did enjoyed and satisfied though she do suggest for more level of intensity to keeping the learners or players engagement and learning continuation.

Third Expert

Third expert she has evaluated interface design as satisfactory and asking for striking colors for all related objects to keep students focus. For content perspective, she also satisfied and enjoyed the journety of the project prototype.

All three experts are happy and satisfied with the interface design and they are all engaged themselves while playing with the project prototype. Based on the heuristic evaluation made, the prototype projects is a successful. As for functionality testing, all prototype functions are tested modularly and tested again after final integration are being done. Testing has been made by the researchers and results are satisfactory where all functions are functioning well. In addition, the prototype project has also been tested to a few group of children aged 7 to 8 years ramdomly choosen to test for the functionality of the prototype project. All functionality results are satisfactory.

\section{CONCLUSION}

Maze with animated puzzle game has been developed for children aged 7 to 8 years old who are facing problem in meta-cognitive thinking to help in strengthen their skill. This application hopefully can be widely used across the community as a tool for strengthen meta-cognitive skill. Maze with animated game puzzle is a challenging game as it uses a critical thinking to solve the task. Also maze with animated puzzle game is interactive to use as it is a computerized puzzle game that use the animation approach. At the design phase, the blocks of the puzzle game that has been designed is used as a reference. It is basically a normal puzzle game but in a digital form. The animation approach is implemented to create a new environment and to attract the users into the game. Maze with animated puzzle game was developed to help children to increase meta-cognitive thinking thinking by solving the task in that game. At the development phase, the prototype was developed based on the designed blocks as a reference. Multimedia element such as animation, audio and picture is included in the application in order to attract attention and concentration of the targeted user. Those multimedia elements can help the children to get a better concentrating and understanding. 


\section{ACKNOWLEDGEMENTS}

The authors would like to thank Ministry of Education (MOE), MALAYSIA and Universiti Teknologi MARA for their financial support to this project under the Fundamental Research Grant Scheme (FRGS) [File No: 600-RMI/FRGS5/3 (132/2015)

\section{REFERENCES}

[1] Suhaili, A. B. H. (2014). Exploring teachers' experiences on integration of higher order thinking skills (HOTS) in teaching of science (Doctoral dissertation, Universiti Malaysia Sarawak).

[2] Malaysia Education Blueprint 2013 - 2025 (Preschool to Post-Secondary Education)

[3] Nor'ain, M. A. B. S., Mazlini, M. T., \& Saad, A. M. I. M. Adventure Based Learning Module in Statistics: Development and Impact on Students Achievement, Critical Thinking and Leaderships Skills.

[4] Phillips, M. (1997). What makes schools effective? A comparison of the relationships of communitarian climate and academic climate to mathematics achievement and attendance during middle school. American educational research journal, 34(4), 633-662.

[5] Neville, K., \& Heavin, C. (2013). Using Social Media to Support the Learning Needs of Future IS Security Professionals. Electronic Journal of e-Learning, 11(1), 29-38.

[6] Mayer, R. E., \& Massa, L. J. (2003). Three facets of visual and verbal learners: Cognitive ability, cognitive style, and learning preference. Journal of educational psychology, 95(4), 833.

[7] Ruggiero, G. M., Stapinski, L., Caselli, G., Fiore, F., Gallucci, M., Sassaroli, S., \& Rapee, R. M. (2012). Beliefs over control and meta-worry interact with the effect of intolerance of uncertainty on worry. Personality and Individual Differences, 53(3), 224-230.

[8] Cranton, P. (1994). Self-directed and transformative instructional development. The Journal of Higher Education, 65(6), 726-744.

[9] Cefai, C., \& Cooper, P. (2010). Students without voices: the unheard accounts of secondary school students with social, emotional and behaviour difficulties. European Journal of Special Needs Education, 25(2), 183-198.

[10] Oxford, R. L. (1995). When emotion meets (meta) cognition in language learning histories. International Journal of Educational Research, 23(7), 581-594.

[11] Loaiza, M. E. R. (2016). Anytime active learning. Illinois Institute of Technology.

[12] Facer, K., Joiner, R., Stanton, D., Reid, J., Hull, R., \& Kirk, D. (2004). Savannah: mobile gaming and learning?. Journal of Computer assisted learning, 20(6), 399-409.

[13] Kirriemuir, J., \& McFarlane, A. (2004). Literature review in games and learning.

[14] Heong, Y. M., Yunos, J. M., Othman, W., Hassan, R., Kiong, T. T., \& Mohamad, M. M. (2012). The needs analysis of learning higher order thinking skills for generating ideas. Procedia-Social and Behavioral Sciences, 59, 197-203.

[15] Johnson, W. L., Vilhjálmsson, H. H., \& Marsella, S. (2005, May). Serious games for language learning: How much game, how much AI?. In AIED (Vol. 125, pp. 306-313).

[16] Hartup, W. W., \& Coates, B. (1967). Imitation of a peer as a function of reinforcement from the peer group and rewardingness of the model. Child development, 1003-1016.

[17] Buchin, K., \& Buchin, M. (2012). Rolling block mazes are PSPACE-complete. Information and Media Technologies, 7(3), 1025-1028.

[18] Rouse, R., \& Illustrator-Ogden, S. (2000). Game design theory and practice. Wordware Publishing Inc..

[19] Kirsh, D. (2009). Problem solving and situated cognition.

[20] Carvalho, J., Guerreiro, T., Duarte, L., \& Carriço, L. (2012, July). Audio-based puzzle gaming for blind people. In Proceedings of the Mobile Accessibility Workshop at MobileHCI (MOBACC).

[21] Diakopoulos, N., Luther, K., \& Essa, I. (2008, October). Audio Puzzler: piecing together time-stamped speech transcripts with a puzzle game. In Proceedings of the 16th ACM international conference on Multimedia (pp. 865868). ACM.

[22] Bohn, J. (2004, April). The smart jigsaw puzzle assistant: Using RFID technology for building augmented realworld games. In Workshop on Gaming Applications in Pervasive Computing Environments at Pervasive (Vol. 2004).

[23] Sutcliffe, A., Bennett, I., Doubleday, A., \& Ryan, M. (1995). Designing query support for multiple databases. In Human-Computer Interaction (pp. 207-212). Springer, Boston, MA. 